\title{
A ATUAÇÃo PROPOSITIVA dA GESTÃo EDUCACIONAL PARA FORTALECIMENTO DE PRÁTICAS DEMOCRÁTICAS NA REDE MUNICIPAL DE ENSINO, EM CONTEXTO FORMATIVO - UM RELATO DE CASO
}

\author{
THE INTENTIONAL PERFORMANCE OF EDUCATIONAL MANAGEMENT TO STRENGTHEN
}

DEMOCRATIC PRACTICES IN THE MUNICIPAL SCHOOL SYSTEM, WITHIN A PROFESSIONAL

DEVELOPMENT CONTEXT - A CASE REPORT

\author{
D Camila Campos Tinoco Fattori \\ Psicopedagoga, Universidade Metodista de São Paulo - SP \\ Santo André - SP - Brasil \\ camila.fattori@comunidadeeducativa.org.br \\ Márcia Cristina da Silva \\ Mestre em Educação, Pontifícia Universidade Católica de São Paulo - PUC-SP \\ São Paulo - SP - Brasil \\ marcia.cristina@comunidadeeducativa.org.br \\ Fernando Eduardo Silva Mendes \\ Bacharel em Relações Internacionais, Faculdade Tancredo Neves - SP \\ São Paulo - SP - Brasil \\ fernando.mendes@comunidadeeducativa.org.br
}

\begin{abstract}
Resumo: A efetivação do papel social da escola está relacionada, entre outros fatores, à sua capacidade de se constituir enquanto espaço de exercício de práticas democráticas. As equipes técnicas das Secretarias de Educação têm o importante desafio de ser indutoras de políticas que possam promover uma cultura de participação nas escolas, incluindo os(as) estudantes, suas famílias, educadores(as), funcionários(as) e comunidade do entorno. Este artigo abordará uma experiência de formação de técnicos(as) de Secretarias Municipais e de gestores(as) escolares, com base na metodologia de Avaliação Participativa INDIQUE (Indicadores de Qualidade da Educação), que permitiu importantes aprendizagens na dimensão da gestão democrática. O uso da ferramenta, aliado a um processo formativo das equipes gestoras, possibilitou a efetivação de práticas e rotinas que contribuíram para a efetiva melhoria das relações e permitiram reforçar o papel da escola como referência de espaço democrático para toda a sociedade.
\end{abstract}

Palavras-chave: Avaliação. Democrática. Educação. Gestão. Institucional.

\begin{abstract}
To be effective as a social player, the school relies, among other factors, on its capacity to constitute itself as a space for the exercise of democratic practices. The technical teams of Public Education Departments face the important challenge of inducing policies that can promote a culture of participation in schools, including students, their families, educators, school employees, and the community as a whole. This article will address an experience of professional development with Education Department staff and school principals based on the participatory assessment methodology INDIQUE (Educational Quality Indicators), which allowed expressive learning in the dimension of democratic management. The use of the tool, along with a process of professional development of the teams, allowed the implementation of practices and routines that contributed to the effective improvement of the relations within the schools, and allowed to reinforce its role as a reference of democratic space for the whole society.
\end{abstract}

Keywords: Evaluation. Democratic. Education. Management. Institutional.

\section{Para citar - ABNT NBR 6023:2018}

FATTORI, Camila Campos Tinoco; SILVA, Márcia Cristina da; MENDES, Fernando Eduardo Silva. A atuação propositiva da gestão educacional para fortalecimento de práticas democráticas na rede municipal de ensino, em contexto formativo - um relato de caso. Cadernos de Pós-graduação, São Paulo, v. 19, n. 1, p. 45-56, jan./jun. 2020. Disponível em: https://doi.org/10.5585/cpg.v19n1.13225. 


\section{Introdução}

A escola constitui-se como um lócus da construção de uma sociedade mais justa, democrática e participativa. Isso se confirma no arcabouço legislativo, nas pesquisas e estudos que induzem a implementação de práticas, rotinas, bem como programas e políticas governamentais que apoiam a viabilização desse princípio em todo o território nacional.

Ela concretiza-se nessa função por meio da efetivação de práticas e rotinas que favoreçam a construção da participação de todos nos processos decisórios de nossa sociedade. Esse princípio, ligado a outros, como a universalização e a obrigatoriedade de oferta e de matrícula de crianças e jovens na educação básica, constituíram-se como estratégias para a viabilização e fomento da participação cidadã em nossa sociedade contemporânea.

No entanto, embora haja ampla fundamentação, bem como apoio por programas e políticas educacionais promovidos pelas diversas instâncias e esferas de governos, é notório o reconhecimento de que especialmente a escola pública brasileira tem enfrentado grandes desafios para implementar as práticas e rotinas mencionadas. Faz-se necessário pensar sobre as razões pelas quais a escola não tem conseguido, com raras exceções, constituir-se, em cada um dos territórios em que atua, como um polo indutor de práticas participativas e democráticas da nossa sociedade.

É fundamental identificarmos a existência espelhada de instâncias de participação nas esferas governamentais responsáveis pela indução e, por consequência, assunção desse princípio em todas as escolas. Referimo-nos especialmente aos órgãos colegiados ligados às Secretarias Municipais e Estaduais de Educação que são responsáveis por promover o controle social e monitorar a implementação de políticas públicas educacionais, sendo compostos por representações de diversos segmentos da sociedade local.

Contudo, apenas a existência dessas instâncias não tem sido suficiente para a viabilização da gestão democrática nas escolas. Então, torna-se necessário dar visibilidade a experiências efetivas com práticas e rotinas voltadas para o fortalecimento do princípio de participação democrática nos espaços escolares, bem como refletir sobre o papel das Secretarias como indutoras desse processo.

O presente artigo visa aprofundar as reflexões sobre uma metodologia voltada à participação social que tem, na avaliação dos(as) autores(as), apresentado resultados importantes. Trata-se da Avaliação Institucional Participativa - INDIQUE ${ }^{1}$, que será apresentada a seguir. Na esteira da análise serão aprofundadas reflexões sobre o potencial desse instrumento e das respectivas práticas na qualificação e fortalecimento dos sistemas municipais de ensino.

\section{Breve contextualização}

A organização em que os(as) autores(as) do artigo trabalham é a Comunidade Educativa 
CEDAC, uma OSCIP² que atua há mais de 20 anos apoiando os(as) profissionais da educação no desenvolvimento de conhecimentos e práticas que resultem na oferta de uma educação pública de qualidade, com foco no aprimoramento contínuo dos processos de ensino, gestão em rede e participação comunitária.

Uma das áreas de formação da referida organização é a gestão educacional e escolar, por meio da qual se atua com técnicos(as) das Secretarias de Educação (principalmente municipais), e também com diretores(as) e coordenadores(as) pedagógicos(as) das escolas da rede. Um de seus programas, no qual a experiência que será relatada ocorreu, implementa ações de formação nos eixos de gestão educacional, gestão escolar e mobilização social, sempre em parceria com as Secretarias Municipais de Educação e as empresas investidas pelo grupo empresarial. A organização da formação se dá através de 4 (quatro) ciclos, sendo que um formador da organização é o responsável pelo encaminhamento formativo e paulatinamente essa formação vai sendo assumida pelas equipes técnicas das Secretarias, de acordo com o princípio da autonomia profissional.

Para realizar tal missão, a equipe da OSCIP desenvolve conhecimentos e metodologias específicos, além de buscá-los em outras organizações parceiras e estudos teóricos da área. Foi assim que, em 2015, agregou a metodologia de Avaliação Participativa Indicadores da Qualidade da Educação - INDIQUE ${ }^{3}$ em um de seus programas de formação. Trata-se de uma metodologia que visa a autoavaliação participativa, possibilitando que escolas ou redes inteiras possam criar situações de avaliação com a comunidade escolar (equipe da escola, estudantes, familiares e comunidade), a partir de indicadores que retratam as dimensões da qualidade da educação. A coleção de materiais que dão suporte à metodologia é dividida em: ensino fundamental, educação infantil e relações raciais, além do guia "O uso da coleção Indicadores na construção participativa de Planos de Educação".

A metodologia INDIQUE fez parte da formação de gestores(as) no programa de 2015 a 2017, compondo uma das temáticas de formação: "Avaliação Participativa para melhoria da Qualidade da Educação". Neste período, 21 (vinte e um) municípios tiveram a oportunidade de refletir a partir dos estudos e aplicação da metodologia. A equipe de formação do programa avaliou de forma muito positiva a efetividade do uso da metodologia INDIQUE em contexto formativo, na medida em que permitiu o exercício de práticas democráticas pelos(as) gestores(as) das escolas e das Secretarias e, ao mesmo tempo, viabilizou um importante espaço de participação para a comunidade. Verificou-se que a sua implementação incidiu, em muitos casos, na ampliação da parceria e da articulação entre as ações das escolas e políticas da rede. Neste artigo abordaremos algumas experiências que demonstram tal potencial, concentrando-nos mais nesse último aspecto. 


\section{Análise sobre o processo formativo para a utilização da avaliação institucional pelas escolas, em parceria com técnicos(as) da rede}

O trabalho em campo iniciou-se pela reflexão sobre educação de qualidade e sobre gestão democrática, ilustrada abaixo por trecho de relatório de uma das formadoras do programa:

Formadora A - Município 1: As discussões sobre o papel dos(as) gestores(as) na gestão democrática foram importantes e dispararam para os grupos de gestores(as) escolares e educacionais algumas questões primordiais, por exemplo a de que não é o fato de ter reunião de pais, conselho de classe, festa de pais etc. que indica que a escola segue com uma gestão democrática. O exercício que propus ao grupo foi apontar dentro de cada iniciativa levantada por eles, sinais de uma gestão democrática.

Alguns comentários dos(as) gestores(as): É preciso que os gestores tenham olhos e ouvidos para os anseios da comunidade. / Olhando por esse viés, temos um longo caminho para percorrer. / Algumas vezes, observo que alguns pais se negam o direito de participar. / Todos envolvidos no processo têm direitos e deveres! / Os pais acham que a escola tem que decidir tudo. / É preciso de um tempo para a construção do diálogo entre família e escola. / Precisamos investir no processo da corresponsabilização nas decisões e iniciativas.

A proposta seguinte se deu com provocações para o conceito de qualidade e foi um sucesso! Disponibilizei imagens para provocar reflexões sobre qualidade: a diferenciação dos olhares de cada ator, a lacuna que existe entre o olhar e a prática, e o conceito de participação de qualidade. Surgiram inquietações, comparações de práticas, dúvidas, observações minuciosas, opiniões semelhantes e distintas, essas foram algumas reações que pude ver no grupo.

Uma das grandes reflexões finais foi: a qualidade vai se constituindo num só processo construtivo, pois mesmo que as pessoas tenham pontos de vista diferentes, elas precisam ir construindo o mesmo conceito de participação, para aí então, planejar ações de melhoria. E o conceito de qualidade precisa ser da rede, não de cada escola ou mesmo cada professor(a) dentro da mesma escola. (grifo nosso)

É comum que os(as) profissionais estejam tão imersos em suas atuações profissionais que tenham dificuldade de identificar e analisar a efetividade das próprias práticas, e isso não é diferente na educação. Por isto, é necessário investir em estratégias que possibilitem um deslocamento do fazer cotidiano para uma visão mais ampla da rede e da escola, e sua função social. Esse trabalho inicial, antes da entrada na metodologia de autoavaliação participativa, é importante para a construção do sentido sobre a formação e também sobre conceitos-chave como qualidade e gestão democrática. Foi fundamental nos processos formativos a discussão prévia com as equipes técnicas das Secretarias, pois possibilitou que esses atores tivessem uma função propositiva nas reflexões com gestores(as) escolares sobre o tema.

Em seguida, os(as) gestores(as) escolares puderam explorar as publicações da Coleção INDIQUE e iniciaram, com suporte da Secretaria, o planejamento de ações para viabilizar a autoavaliação. Ressalta-se aqui uma estrutura importante do programa que foi uma das chaves para garantir a qualidade dessa experiência: a atuação dos(as) técnicos(as) formadores(as) das Secretarias ${ }^{4}$. Foi com esse apoio que os(as) gestores(as) escolares de todos os municípios fizeram planejamentos das ações necessárias para a realização do INDIQUE na rede. Esses planejamentos foram feitos coletivamente por todos(as) os(as) gestores(as) escolares que, posteriormente, os 
compartilharam com suas equipes escolares e ampliaram as ações planejadas, de acordo com os contextos de cada realidade.

Seguem algumas reflexões de técnicas formadoras do Município 1 em relação à reunião realizada com gestores(as) escolares para que iniciassem o planejamento geral:

Formadora A - Município 1: Escolhemos o vídeo "Desafios para a Avaliação institucional e condições para a participação", porém, antes de assisti-lo, propusemos que os(as) participantes relacionassem quais seriam os desafios para a realização da avaliação. Eles(as) relacionaram o seguinte: mobilizar a comunidade, transporte, horário; garantir a participação, divulgação, diálogo (ouvir, falar, discutir, negociar, argumentar...), linguagem apropriada; aceitar críticas.

Após o vídeo, relacionamos coletivamente os desafios trazidos e os apontados anteriormente por eles(as). Concluímos que o vídeo ampliou a visão sobre os desafios; sobre a importância da devolutiva pública e do uso dos resultados; que avaliação não pode servir de punição; que é necessário mudar a concepção de avaliação; ter motivação inicial e manutenção da motivação.

Nesse ponto da reunião, as equipes concluíram que precisam cuidar da comunicação da avaliação à comunidade escolar, para que essa avaliação não seja vista como um instrumento de punição ou de ranqueamento de escolas. O primeiro grande desafio, então, é conversar com a equipe, esclarecendo os objetivos da avaliação INDIQUE. Outro aspecto importante é cuidar da mobilização inicial para garantir participação e cuidar da manutenção da motivação, para que essa avaliação sirva como instrumento de desenvolvimento.

Neste exemplo é possível observar como o trabalho formativo conduzido pela dupla de técnicas formadoras da Secretaria foi importante para garantir o processo reflexivo em relação ao papel da autoavaliação no interior das escolas, para que as duplas gestoras considerassem o quanto é importante a parceria com a comunidade, pois como em qualquer avaliação são observados pontos positivos e negativos, e será preciso contar com a abertura da equipe para ouvir tais pontos, como também para pensar em alternativas de melhoria dos processos. Neste sentido, a escuta precisa ser desenvolvida continuamente como ponto estratégico para uma gestão democrática.

Outra reflexão importante nesse processo foi sobre a ação relacionada à comunicação com os(as) responsáveis. Vejamos o registro de uma das formadoras do programa sobre o que essa problematização com as duplas gestoras promoveu de reflexão:

Formadora A - Município 1: Na continuidade, solicitei ao grupo que levantasse as características das famílias de sua comunidade escolar, com a intenção de fazer um convite para os(as) diretores(as) e coordenadores(as) olharem para as famílias atendidas pela escola e pensarem na mobilização dessas mesmas famílias a partir de suas características. As discussões e reflexões começaram a aquecer já no levantamento dos perfis das famílias e no planejamento das ações propostas para mobilização, e tomaram forma com a questão colocada por mim: Em que medida as ações planejadas para os desafios no processo da aplicação dos INDIQUES garantem o atendimento das especificidades das famílias?

Essa estratégia contribuiu para que o grupo refletisse e compreendesse ainda mais as oportunidades e os desafios de uma gestão participativa, através do processo de mobilização da (e na) escola, para públicos diferentes com características distintas.

Reuni as características levantadas em 5 grupos e pedi para os(as) diretores(as) e coordenadores(as) se dividirem, com o objetivo de planejarem ações de mobilização dos(as) familiares, considerando essas mesmas características. 
Com o apoio da formadora e das técnicas da Secretaria, neste contexto reflexivo, os(as) gestores(as) listaram algumas ações de mobilização, pensando nos diferentes perfis das famílias de suas comunidades. Nota-se nesse e em outros momentos a grande diferença que a abordagem formativa pode proporcionar, de forma que o processo é tão relevante quanto o ponto de chegada. Seria mais rápido e prático chegar com um rol de possibilidades de mobilização dos(as) familiares, apresentá-las aos(às) participantes e agregá-las ao plano de ação. Porém, isto não garantiria que os(as) gestores(as) ampliassem a predisposição para estar realmente em contato com as famílias, bem como de preparar suas equipes para isso. A possibilidade de se usar espaços formativos em grupo para isto também merece destaque. Cada escola tem uma realidade e uma cultura específica e se torna interessante que os(as) gestores(as) possam ouvir uns aos outros para poder ampliar seus referenciais. Um(a) diretor(a) que não tem tanta predisposição para uma atuação democrática pode dar-se conta disto apenas quando encontra um(a) que tenha, pois até então a sua realidade era a única disponível como padrão.

Quando as técnicas formadoras acompanharam a condução da formadora nessas discussões, frequentemente foi observado que faziam análises sobre a relevância de se contemplar esse tipo de discussão em outros espaços, considerando que a formação dos(as) profissionais de educação precisa levar em conta também a sua dimensão atitudinal.

Por meio dos trechos do relatório da formadora, é possível verificar o impacto dessa experiência:

\footnotetext{
Formadora A - Município 1: Logo no início do encontro, o grupo estava muito ansioso para me contar sobre a aplicação dos Indicadores da Qualidade na escola. Entre tantas observações, destaco uma: o fato de poucos pais terem participado da avaliação, apesar da grande mobilização que foi feita pelos(as) diretores(as), coordenadores(as) e também pela equipe da Secretaria de Educação (34\% da Educação Infantil e 39\% do Ensino Fundamental). Apenas uma escola teve participação de quase que 100\% dos pais, que é uma escola que tem um conselho participativo, constante e com muitos outros indícios de gestão democrática. Segundo uma técnica formadora da Secretaria, essa constatação significou um abismo enorme entre a escola e a comunidade. A sensação que dá é de que os pais não conhecem a escola, que não são muito convidados a participar da escola, que não são ouvidos. Nós, enquanto Secretaria, temos muito a fazer... os(as) diretores(as) se incomodaram com a falta dos pais e com o que isso representou. Com certeza a pouca presença dos pais escancarou um problema muito sério, que acho que nenbum de nós tinha consciência. (grifo nosso)
}

Observamos como a importância da estratégia formativa para a introdução da metodologia se faz presente. A equipe da Secretaria e os(as) gestores(as) escolares se empenharam na realização do evento, para que a autoavaliação participativa pudesse contar com uma representação significativa da comunidade, e se surpreenderam com o baixo quórum. Uma situação como essa poderia facilmente frustrar os(as) profissionais, a ponto de representar, ao final, uma barreira na relação da escola com a família, e não a ponte almejada. No entanto, as reflexões anteriores sobre o papel social da escola e sobre a necessidade de um olhar técnico a respeito da relação família e 
escola subsidiaram as reflexões. Assim, o ocorrido tornou-se um problema a ser enfrentado, e não a ser apenas lamentado, tanto pelas equipes escolares como também pelas equipes técnicas das Secretarias, pois se há um alto índice de pouca participação de comunidades no processo, este é também um desafio da própria rede. Assim, revelou-se outra questão a ser enfrentada pelas equipes técnicas das Secretarias, que sempre precisam pensar em estratégias para auxiliar as equipes escolares a superar desafios.

Como exemplo do trabalho realizado pelos(as) técnicos(as) formadores(as) junto aos(às) gestores(as) escolares da rede, segue um quadro, elaborado por uma dupla de técnicas formadoras de um dos municípios, sobre o que observaram nas escolas no dia da aplicação do INDIQUE:

Quadro 1 - Reflexões das técnicas formadoras sobre a aplicação do INDIQUE na rede

\begin{tabular}{|c|c|c|}
\hline Ponto de reflexão & Destaque & Ponto de atenção \\
\hline $\begin{array}{l}\text { Observações gerais sobre } \mathrm{O} \\
\text { envolvimento da comunidade } \\
\text { com a proposta de autoavaliação. }\end{array}$ & $\begin{array}{l}\text { A maioria dos(as) responsáveis } \\
\text { permaneceu até o fim da plenária } \\
\text { em todas as escolas participantes. } \\
\text { / Participação dos(as) alunos(as) } \\
\text { dos } 5^{\mathrm{o}_{\mathrm{s}}} \text { anos nas escolas de Ensino } \\
\text { Fundamental. }\end{array}$ & $\begin{array}{l}\text { Poucos pais participaram da avaliação. / } \\
\text { Durante a avaliação, nem sempre } \\
\text { ocorreram discussões. }\end{array}$ \\
\hline $\begin{array}{l}\text { Organização da escola para o } \\
\text { evento. }\end{array}$ & $\begin{array}{l}\text { Café da manhã. / Acolhimento e } \\
\text { recepção. / Fala de abertura. / } \\
\text { Organização das salas e materiais. }\end{array}$ & $\begin{array}{l}\text { Faltou transporte para alguns bairros } \\
\text { atendidos por uma escola e isso pode } \\
\text { ter impactado no baixo índice de } \\
\text { participação da comunidade. }\end{array}$ \\
\hline $\begin{array}{l}\text { Aprendizagens } \operatorname{dos}(\mathrm{as}) \\
\text { diretores(as) nesse processo. }\end{array}$ & $\begin{array}{l}\text { Distribuição de tarefas com toda a } \\
\text { equipe no interior das escolas. / } \\
\text { Elaboração do plano de ação para } \\
\text { garantir o encaminhamento das } \\
\text { ações. / Compreensão de que o } \\
\text { envolvimento da comunidade é } \\
\text { um processo que precisa ser } \\
\text { construído e não se resume a uma } \\
\text { única ação. }\end{array}$ & $\begin{array}{l}\text { Mostra-se necessária a proposição por } \\
\text { parte das escolas de mais momentos } \\
\text { nos quais a comunidade tenha a } \\
\text { oportunidade de participar } \\
\text { democraticamente. }\end{array}$ \\
\hline
\end{tabular}

Fonte: Relatórios internos do programa, 2015.

Neste registro já é possível identificar o quanto a estratégia de observação utilizada pelas técnicas formadoras é importante no processo de acompanhamento das ações das escolas pelas equipes técnicas da Secretaria, pois, ao incluírem a coluna de ponto de atenção, puderam antecipar os possíveis encaminhamentos que as equipes escolares teriam de realizar. Verificaram, ainda, aqueles que seriam de responsabilidade da equipe da Secretaria, por exemplo a continuidade do processo formativo dos(as) diretores(as) com conteúdos relacionados à parceria família e escola, bem como sobre o papel da gestão para o fortalecimento democrático.

Outra etapa importante nesse processo formativo relaciona-se aos resultados das autoavaliações, tanto na perspectiva das equipes escolares como das equipes técnicas das Secretarias. Seguem abaixo 2 quadros que retratam os resultados da autoavaliação no interior de uma escola e as prioridades que a comissão escolar encaminhou a partir do cenário. A gradação de 
cada item se dá no "formato farol", com a cor verde sinalizando o que está satisfatório, a amarela o que precisa de atenção e a vermelha classificando o que está crítico:

Quadro 2 - Resultado final da aplicação do INDIQUE (de três dimensões) - Escola B - Município 2

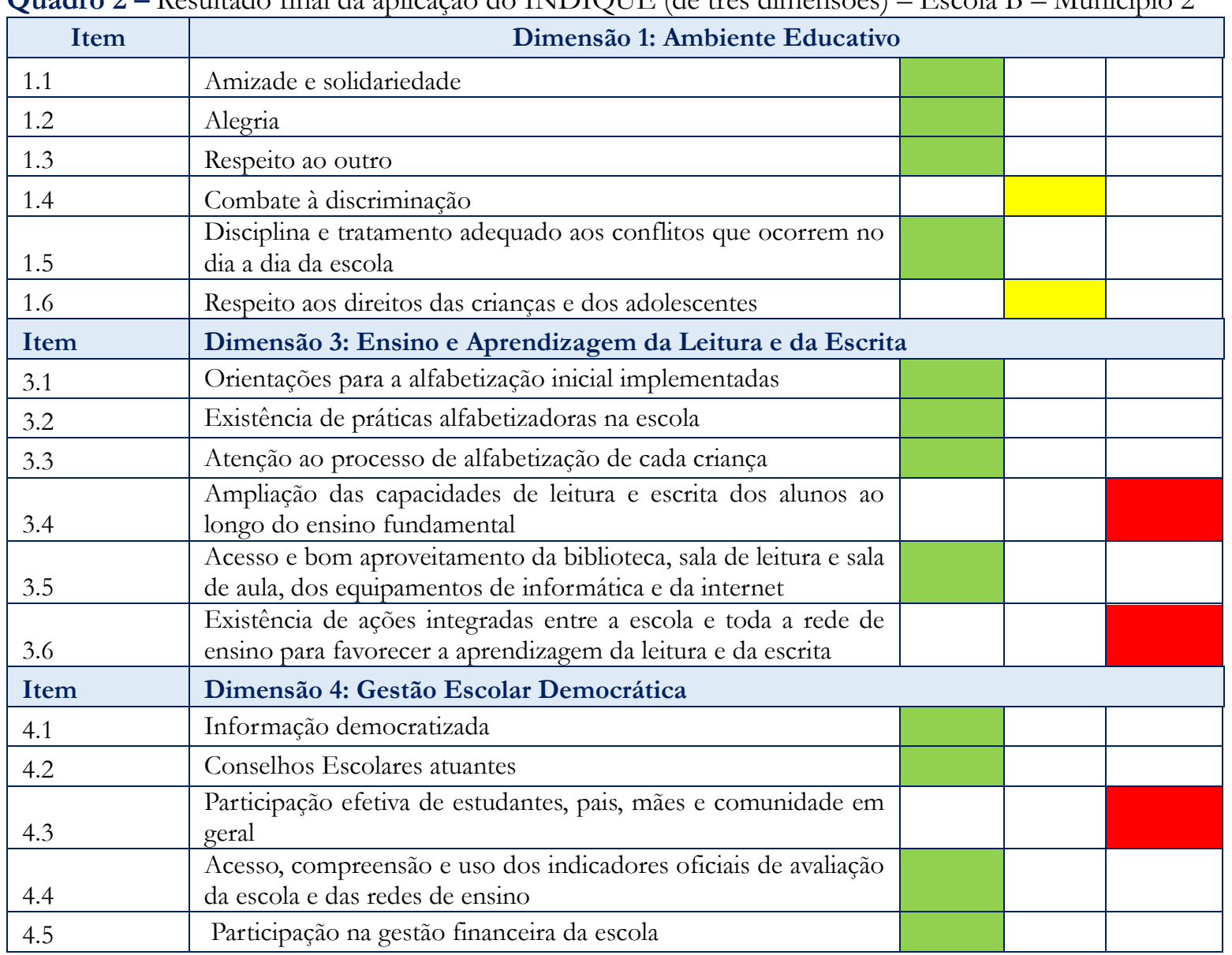

Fonte: Relatórios internos do programa, 2015.

Quanto aos encaminhamentos feitos pelas equipes de Secretarias a partir dos resultados das escolas, será apresentado inicialmente o trecho de um registro de uma equipe de Secretaria de um dos municípios sobre o trabalho com as escolas que aplicaram o INDIQUE:

Os resultados apontados na aplicação do INDIQUE 2015 foram ponto de partida para a elaboração do Plano de Intervenção da Rede, tendo como objetivo possibilitar uma maior compreensão, bem como discussões acerca dos desafios da Rede e do trabalho da Secretaria.

Nessa direção, a SEMED solicitou que cada escola, diante de seus resultados, definisse quatro dimensões prioritárias possíveis de serem trabalhadas a partir das potencialidades existentes na própria escola.

Assim, foram apresentados alguns questionamentos, a saber:

Diante dos resultados do INDIQUE aplicado em nossa Rede, o que é necessário ser feito para transformar a realidade identificada?

Como deve ser o Plano de Ação da escola para melhorar o resultado apresentado? O que precisamos realizar e quando?

Essa proposta também foi desenvolvida pelo grupo de Gestão Educacional da Secretaria de Educação, objetivando a elaboração do Plano de Ação da Rede a partir dos resultados gerais das dimensões priorizadas por todas as escolas que participaram do INDIQUE. 
Assim, cada setor propôs ações para a melhoria dos resultados evidenciados nos dados do INDIQUE 2015, a partir da definição das dimensões: Gestão Escolar Democrática; Formação e Condições de Trabalho; Ambiente Físico Escolar; e Ambiente Educativo."

Essa equipe elaborou gráficos com os percentuais de respostas de todos(as) os(as) participantes da autoavaliação nas 29 (vinte e nove) escolas, analisando o que era geral, o que era específico e procurando estabelecer correlações.

A partir desses resultados, a equipe técnica da Secretaria Municipal de Educação elaborou um instrumento para ser preenchido por cada um dos setores da pasta. A proposta era que os(as) profissionais pudessem pensar ações que visassem qualificar as dimensões identificadas como mais deficitárias pelas escolas e suas respectivas comunidades. Abaixo, apresenta-se o modelo de um dos instrumentos disponibilizados aos setores, tendo em vista o propósito aqui mencionado:

Quadro 3 - Instrumento de planejamento das ações da Secretaria - Município 3

\begin{tabular}{|c|c|c|c|c|}
\hline \multirow{2}{*}{\multicolumn{5}{|c|}{$\begin{array}{c}\text { PREFEITURA MUNICIPAL 3 - SECRETARIA MUNICIPAL DE EDUCAÇÃO } \\
\text { Proposta de ações para superação dos problemas detectados no INDIQUE }\end{array}$}} \\
\hline & & & & \\
\hline \multicolumn{5}{|c|}{ Dimensão 5: Formação e condições de trabalho dos profissionais da escola } \\
\hline 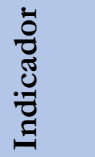 & $\begin{array}{l}\text { Questões avaliadas pelas escolas } \\
\text { que apresentaram maior fragilidade }\end{array}$ & $\begin{array}{l}\text { Ações propostas } \\
\text { pelo Setor para a } \\
\text { SEMED }\end{array}$ & $\begin{array}{l}\text { Setores } \\
\text { envolvidos/ } \\
\text { Responsáveis }\end{array}$ & $\begin{array}{l}\text { Período de } \\
\text { realização }\end{array}$ \\
\hline \multirow{4}{*}{ 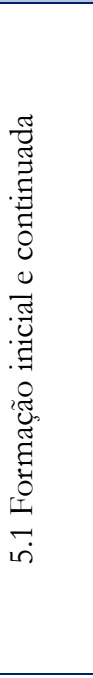 } & $\begin{array}{l}5.1 .2 \text { - A escola ou a Secretaria da } \\
\text { Educação oferecem permanentemente } \\
\text { cursos ou ações de formação para } \\
\text { professores e demais funcionários da } \\
\text { rede. }\end{array}$ & & & \\
\hline & $\begin{array}{l}5.1 .3 \text { - Nestes cursos ou ações de } \\
\text { formação, há vagas suficientes para } \\
\text { formação de todos. }\end{array}$ & & & \\
\hline & $\begin{array}{l}\text { 5.1.6 - Professores e demais } \\
\text { funcionários da escola participam de } \\
\text { formações que os ajudam a trabalhar } \\
\text { com alunos com deficiência? }\end{array}$ & & & \\
\hline & $\begin{array}{l}5.1 .7-\text { A escola utiliza portais } \\
\text { educacionais (como EducaRede, Portal } \\
\text { do Professor do MEC, entre outros) } \\
\text { para subsidiar a formação dos seus } \\
\text { profissionais? }\end{array}$ & & & \\
\hline \multirow{3}{*}{ 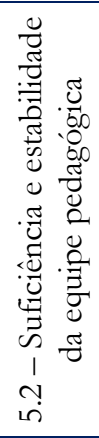 } & $\begin{array}{l}5.2 .2 \text { - O número de funcionários é } \\
\text { suficiente para o bom funcionamento } \\
\text { da escola? }\end{array}$ & & & \\
\hline & $\begin{array}{l}\text { 5.2.3 - A escola possui profissionais de } \\
\text { apoio pedagógico (exemplo: } \\
\text { coordenador, supervisor } \\
\text { psicopedagogo, técnicos das áreas de } \\
\text { ensino) em quantidade suficiente? }\end{array}$ & & & \\
\hline & $\begin{array}{l}5.2 .4-\text { Os professores e demais } \\
\text { profissionais da escola contam com um } \\
\text { plano de carreira? }\end{array}$ & & & \\
\hline
\end{tabular}

Fonte: Relatórios internos do programa, 2015. 
A elaboração das ações ocorreu considerando as referências técnicas para cada dimensão e também procurou-se garantir a intersetorialidade. O programa estimulou que a escuta à população fosse ampliada por meio da elaboração de comitês por escola ou por meio da articulação com o Conselho Escolar, de forma que a implementação das ações fosse acompanhada pela sociedade no âmbito local.

Libâneo, Oliveira e Toshi (2012, p. 512) tratam de estilos de gestão como: a) técnicocientífico, em que se privilegia as normas e regras e o controle do comportamento das pessoas; b) autogestionário, outro extremo em que, a partir de um posicionamento mais crítico, se dá pouca ênfase a práticas de gestão mais estruturadas, incidindo em pouco acompanhamento dos processos; e c) democrático-participativo, que é o estilo de gestão exemplificado nessa experiência, na medida em que "acentua tanto a necessidade de estabelecer objetivos e metas quanto a de prever formas organizativas e procedimentos mais explícitos de gestão e articulação das relações humanas". Por fim, ainda baseados nesses autores (2012), é possível concluir que:

\begin{abstract}
A comunidade deve ser o espaço público em que se discute o conhecimento, a organização curricular, as relações sociais, os modos e critérios de avaliação, as normas. Esse caráter de diálogo e de compartilhamento de significados entre as pessoas da comunidade escolar possibilita à escola como um todo adquirir experiências, acumular recursos cognitivos e operacionais, construir competências coletivas. Ou seja, a instituição torna-se uma organização aprendiz, um espaço de aprendizagem contínua, em que a organização aprende com seus membros e vice-versa (LIBÂNEO et al., 2012, p. 518).
\end{abstract}

\title{
Considerações finais
}

A realização da formação para a aplicação da autoavaliação participativa dessas redes, ainda que em um processo inicial, revelou-se como estratégia potente para mobilizar a comunidade escolar em torno da qualidade da educação socialmente referenciada.

Além disso, o processo vivido foi o maior resultado, na medida em que permitiu que os(as) gestores(as) colocassem em jogo suas percepções e práticas em torno da gestão democrática. Os desafios de relacionamento da escola e comunidade, reconhecidamente amplos no contexto educacional, se tornaram oportunidades para reflexão e busca conjunta de estratégias de implementação, ampliando a percepção dos(as) participantes como representantes de uma rede, com um foco comum.

A escolha de procedimentos e estratégias metodológicas colocadas em jogo nos contextos formativos descritos anteriormente, fomentou a ampliação dos significados e percepções dos grupos que dela fizeram parte.

Nesse sentido, há que se concluir preliminarmente que, além da existência de órgãos colegiados que instituam a prática de gestão democrática, é preciso investir em estratégias para a 
tomada de consciência sobre sua importância, principalmente aquelas que fortalecem processos de diálogos em contexto formativo.

A abordagem formativa que privilegie a discussão e ressignificação das representações sociais individuais, construídas no bojo de suas respectivas trajetórias pessoais e profissionais, podem potencializar esses processos reflexivos e, por consequência, favorecer a mudança de prática na perspectiva da viabilização da gestão democrática. Define-se representações sociais em consonância com Jodelet (1986), como:

\footnotetext{
Uma forma e conhecimento específico, o saber de senso comum, cujos conteúdos manifestam a operação de processos generativos e funcionais socialmente caracterizados. No sentido mais amplo, designam uma forma de pensamento social. As Representações Sociais são modalidades de pensamento prático voltadas à comunicação, à compreensão e ao domínio do ambiente social, material e ideal. (JODELET, 1986, p. 474)
}

Diante dessa análise e das conclusões preliminares apontadas acima, demonstra-se evidente o potencial uso da Avaliação Institucional Participativa para a construção de objetivo, foco e, por consequência, pactuação de metas comuns que servirão sobremaneira para a elaboração de instrumentos institucionais de planejamento da rede de ensino que possam estar ancorados nesses objetivos comuns.

É importante que acrescentemos outro aspecto que advém desse processo de implementação da avaliação institucional para a definição de prioridades a partir da compilação dos resultados de todas as escolas envolvidas, que é a necessidade de a equipe técnica saber sistematizar os dados em informação, conforme orientação que o Programa de Apoio aos Dirigentes Municipais de Educação (PRADIME) já antecipou em seus Cadernos Orientadores para os(as) gestores(as) educacionais:

\footnotetext{
A finalidade de se desenvolver uma sistemática de avaliação que produza informações para subsidiar a definição de diretrizes e parâmetros da política, o aprimoramento das ações em sua execução e a apreciação de seus resultados e impactos é a de constituir um instrumento de gestão da política educacional que sirva à construção da qualidade social da educação. (PRADIME, Caderno 1, p. 158).
}

Esse conjunto de medidas poderá influenciar positivamente a legitimação das políticas públicas educacionais desenvolvidas nas redes de ensino, favorecendo um maior pertencimento da realidade e das necessidades da rede pelo(a) gestor(a) local, inclusive na interface da viabilização do pacto federativo e/ou do sistema nacional de educação, uma vez que estarão materializadas no foco de atuação desse(a) gestor(a) suas prioridades e necessidades, expressas pelos anseios manifestados por toda a comunidade escolar durante a avaliação institucional participativa. 


\section{Referências}

JODELET, Denise. La representacion social: fenomenos, concepto y teoria. In: MOSCOVICI, Serge (org.). Psicología social II. Barcelona: Ediciones Paidós, 1986. p. 469-494.

LIBÂNEO, José Carlos; OLIVEIRA, João Ferreira de; TOSCHI, Mirza Seabra. Educação escolar: políticas, estrutura e organização. São Paulo: Cortez, 2012.

PRADIME (Programa de Apoio aos Dirigentes Municipais de Educação). Ministério da Educação. Secretaria de Educação Básica. Caderno de textos. Brasília, DF: Ministério da Educação, 2006. v. 1.

\section{Notas}

${ }^{1}$ Desde 2003, a Ação Educativa, com apoio do UNICEF e do MEC, vem desenvolvendo os Indicadores da Qualidade na Educação, instrumento de autoavaliação institucional que visa o envolvimento de toda a comunidade escolar em processos de melhoria da qualidade educativa. O instrumento consiste numa proposta metodológica de avaliação participativa e em um conjunto de indicadores por meio dos quais a comunidade julga a situação de diferentes aspectos de sua realidade, identifica prioridades, estabelece planos de ação, implementa e monitora seus resultados. Disponível em: http://www.indicadoreseducacao.org.br/o-que-e-a-colecao-2/. Acesso em: 18 fev. 2019.

2 Organização da Sociedade Civil de Interesse Público.

${ }^{3}$ Metodologia e materiais disponíveis em: http://www.indicadoreseducacao.org.br/. Acesso em: 18 fev. 2019.

4 Tratam-se de dois ou duas técnicos(as) da Secretaria que são indicados(as) pelo(a) Secretário(a) e se tornam parceiros(as) mais próximos(as) do(a) formador(a) da OSCIP, assim como das duplas gestoras das escolas participantes, criando condições de maior diálogo entre as ações das escolas e as propostas da rede. Esses(as) profissionais acompanham de perto a preparação das pautas, a realização da reunião e, no período interciclo (entre as idas presenciais do/a formador/a a campo), apoia os(as) gestores(as) escolares na implementação das atividades propostas, garantindo também que a concepção subjacente seja garantida. 